\title{
CD95 ligand-dependant endothelial cell death initiates oral mucosa damage in a murine model of acute graft versus host disease
}

\author{
Christophe Deschaumes ${ }^{1,2, *}$, Laurence Verneuil ${ }^{1, *}$, Marjan Ertault-Daneshpouy $^{2}$, Homa Adle-Biassette ${ }^{3}$, \\ Françoise Galateau ${ }^{4}$, Fadela Aïnoun ${ }^{1}$, Juliette Micic-Polianski ${ }^{1}$, Anne Janin ${ }^{2}$ and Jean C Ameisen ${ }^{1}$
}

Oral mucosa lesions are one of the common pathological consequences of acute graft versus host disease (aGVHD), the major complication of allogeneic bone marrow transplantation caused by mature $\mathrm{T}$ lymphocytes of donor origin. Oral mucosa damage in aGVHD is characterized by apoptosis induction in the basal keratinocytes, associated with immune effector T-cell infiltration, but its pathogenesis remains unclear because these lesions might result from the patient conditioning therapy that includes radiation and/or chemotherapy. Here, using a murine model of aGVHD that does not involve any conditioning treatment, we show that the earliest detectable oral mucosa lesion is apoptosis of the endothelial cells from chorion capillaries, which precedes basal keratinocyte apoptosis induction. Neither vascular damage nor epithelial-cell death occurred in recipients of allogeneic lymphocytes from CD95 ligand (CD95L)-defective mice. Our findings indicate that oral mucosa lesions in aGVHD are initiated by endothelial-cell death and require CD95L expression by the allogeneic lymphocytes. This early vascular damage may contribute to the induction of further tissue damage in the oral mucosa, through the induction of hypoxia and vascular leakage of immune cells or soluble proapoptotic mediators.

Laboratory Investigation (2007) 87, 417-429. doi:10.1038/labinvest.3700541; published online 5 March 2007

KEYWORDS: apoptosis; CD95 ligand; cell death; endothelial cells; graft versus host disease; oral mucosa

Acute graft versus host disease (aGVHD), the major complication of allogeneic bone marrow grafting, is an immunopathological disease caused by mature allogeneic lymphocytes of donor origin present in the graft. ${ }^{1-4}$ Although the classical target organs of aGVHD are the skin, the liver and the digestive tract, one of the common clinical consequences of aGVHD is the induction of oral mucosa lesions that occur in around $70 \%$ of patients. ${ }^{5-10}$ Histological lesions in the oral mucosa are characterized by basal keratinocyte apoptosis, ${ }^{11,12}$ and often evolve into chronic lichenoid lesions $^{10,13}$ that may, as idiopathic lichen, favor the development of spinocellular cancer. ${ }^{14,15}$ Previous studies using several different murine models have suggested that the pathogenesis of GVHD lesions in the liver, skin and digestive tract might involve either death ligands from the tumor necrosis factor (TNF) family, such as the CD95 ligand (CD95L) or $\mathrm{TNF} \alpha$, expressed or released by allogeneic lymphocytes, ${ }^{4,16-22}$ or perforine/granzyme, released by allogeneic lymphocyte granules. ${ }^{4,17,23}$ However, the potential contribution of these effector molecules to the pathogenesis of oral mucosa lesions remains unknown. The pathogenesis of acute oral mucosa lesions in aGVHD patients is unclear because they may result from immune-mediated aggression, from the conditioning therapy, which includes radiotherapy and/or chemotherapy, ${ }^{24,25}$ or from a combination of both.

Most murine models devised to elucidate the pathogenesis of aGVHD involve the transfer of allogeneic mature lymphocytes, but several of these models raise complex problems of interpretation, owing either to recipient conditioning, or

'INSERM U 552, IFR 02, Faculté de Médecine Xavier Bichat, Université Paris 7, AP-HP, Paris, France; ${ }^{2}$ INSERM U 728, Department of Pathology, AP-HP, Hôpital St-Louis, Université Paris 7, Paris, France; ${ }^{3}$ Service d'Anatomie et de Cytologie Pathologiques, Hôpital Bichat-Claude Bernard, AP-HP, Paris, France and ${ }^{4}$ Service d'Anatomopathologie, CHU Caen, Caen, France

Correspondence: Dr L Verneuil, MD or Dr JC Ameisen, MD, PhD, INSERM U 552, Faculté de Médecine Xavier Bichat, 16 rue Henri Huchard, 75870 Paris Cedex 18 , France. E-mails: verneuil@bichat.inserm.fr or ameisen.j@@gmail.com

${ }^{*}$ These authors contributed equally to this work. 
to the presence of mature lymphocytes of recipient origin in the parent to F1 model. ${ }^{4,16-20,23,26-28}$ To avoid these problems, we have developed the simplest possible experimental model of aGVHD: injection of mature splenic lymphocytes from immunocompetent mice into major histocompatibility complex (MHC) I- and II-mismatched immunodeficient severe combined immunodeficient (SCID) recipient mice. ${ }^{22}$ Using this murine model, we recently identified disseminated endothelial-cell apoptosis and vascular damage as the first detectable lesion of aGVHD. ${ }^{22}$ Endothelial-cell death and vascular damage occurred not only in the classical target organs of aGVHD, namely the liver, skin and digestive tract, but also in the kidneys, lungs, heart and brain. More generally, we identified disseminated endothelial-cell apoptosis and vascular loss as an early consequence of CD95 engagement in vivo, whether induced by agonistic anti-CD95 antibodies, oligomerized soluble recombinant CD95L or CD95Lexpressing allogeneic lymphocytes. ${ }^{22}$

The idea that endothelial cells might constitute an early and critical target of allogeneic immune responses was first suggested 25 years ago by a study from Dvorak et al which identified microvascular damage preceding epithelial lesions during first-set skin allograft rejection in man. ${ }^{29}$ Fifteen years ago, endothelial-cell injury was also described as a feature of cutaneous lesions in patients undergoing aGVHD. ${ }^{30}$ Four years ago, concomitantly with our report of the early induction of CD95L-dependant disseminated endothelial cell death and vascular damage in a murine model of aGVHD, ${ }^{22}$ endothelial-cell injury and microvessel loss, associated with perivascular CD8 T-cell infiltration were reported in the skin of patients with chronic GVHD, ${ }^{31}$ and 2 years later, in the digestive tract of patients with severe forms of GVHD, ${ }^{32}$ pericapillary hemorrhages being correlated to disease severity in the latter case.

Here, we investigated the potential involvement of endothelial-cell death in the pathogenesis of oral mucosa damage in aGVHD. We performed a kinetic analysis in our experimental model of aGVHD, ${ }^{22}$ based on the injection of mature splenic lymphocytes from immunocompetent mice into MHC I and II-mismatched immunodeficient SCID recipient mice, in the absence of any conditioning treatment. We used both a model of progressive aGVHD, induced by the transfer of $2.5 \times 10^{7}$ allogeneic lymphocytes, and a model of very acute GVHD caused by the transfer of high numbers $\left(10^{8}\right)$ of allogeneic lymphocytes. ${ }^{22}$ We focused our study on the tongue mucosa because of the constant clinical alteration on its lateral borders during oral lesion in human aGVHD. ${ }^{12}$ We investigated whether (i) allogeneic lymphocytes may be sufficient to cause oral mucosa lesions in the absence of any conditioning treatment; (ii) endothelial-cell death may precede the induction of epithelial-cell apoptosis in the oral mucosa; and (iii) induction of vascular damage in the oral mucosa may involve CD95L expressed or released by the allogeneic lymphocytes.

\section{MATERIALS AND METHODS}

\section{Mice}

Six to seven-week-old wild type (wt) C57BL/6 (H2b) and $\mathrm{BALB} / \mathrm{c}(\mathrm{H} 2 \mathrm{~d})$ mice were obtained from Iffa Credo Laboratory (L'Arbresle, France) and lymphoproliferation (lpr)/ C57BL6 (H2b), generalized lymphoproliferation disease $(\mathrm{gld}) / \mathrm{C} 57 \mathrm{BL} 6(\mathrm{H} 2 \mathrm{~b})$ and SCID/C57BL6 (H2b) mice from Jackson Laboratory (Bar Harbor, ME, USA) and SCID/ $\mathrm{BALB} / \mathrm{c}(\mathrm{H} 2 \mathrm{~d})$ mice from Harlan Laboratory (Oxen, United Kingdom). SCID mice were housed in sterilized cages with filter cap and received sterilized water and chow ad libitum, and all mice were allowed to rest for 1 week before the experiments were conducted. All the mouse studies reported in this study have been approved by the Animal Housing and Experiment Board of the French government.

\section{Injection of Allogeneic or Syngeneic Lymphocytes}

Lymphocytes were isolated from the spleen of killed mice by density gradient centrifugation cell separation with Lympholyte-M (TEBU, Le Perray en Yvelines, France), after lysis of red blood cells in tris-ammonium chloride buffer (Biofluids, Rockville, MD, USA). Following washing in RPMI supplemented with $10 \%$ fetal calf serum, $2 \mathrm{mM} \mathrm{L}$-glutamine and $1 \mathrm{mM}$ pyruvate (Gibco BRL, Rockville, MD, USA), macrophages and monocytes were depleted by plastic adherence at $37^{\circ} \mathrm{C}$ in $5 \% \mathrm{CO}_{2}$ for $2 \mathrm{~h}$. Cell populations were analyzed with a FACScan (Becton Dickinson Immunocytometry Systems, Mountain View, CA, USA) following labeling with phycoerythrin-conjugated monoclonal antibody (mAb) against mouse Thy-1.2, Cy-Chrome conjugated $\mathrm{mAb}$ against mouse B220, fluorescein isothiocyanateconjugated $\mathrm{mAb}$ against mouse natural killer cells and isotype-matched control immunoglobulin (Pharmingen, San Diego, CA, USA) at $4^{\circ} \mathrm{C}$ for $30 \mathrm{mn}$. Splenic lymphocytes contained around 40\% $\mathrm{T}$ lymphocytes and their viability, controlled with Trypan blue exclusion, was more than $95 \%$. Cells were then suspended at $2.5 \times 10^{7}$ or $10^{8}$ viable cells per $500 \mu \mathrm{l}$ of RPMI and were immediately injected intra-peritoneally into recipient. Allogeneic cell transfers were from C57BL/6 or $l p r / C 57 B L 6$ and gld/C57BL6 into SCID BALB/c recipients. Syngeneic transfers were from BALB/c into SCID $\mathrm{BALB} / \mathrm{c}$ recipients or from $\mathrm{C} 57 \mathrm{BL} / 6$ or $\mathrm{lpr} / \mathrm{C} 57 \mathrm{BL} 6$ and $\mathrm{gld} /$ C57BL6 into SCID C57BL/6 recipients. When so indicated, a caspase-8 inhibitor peptide (z-IETD-fmk) $(500 \mu \mathrm{g})$ from Calbiochem Laboratory (San Diego, CA, USA) was injected intravenously, under brief ether anesthesia, in a $200 \mu \mathrm{l}$ sterile isotonic solution. When not killed, recipient mice were monitored and scored daily for clinical manifestations of aGVHD, such as weight loss of more than $20 \%$, associated with posture modification (hunching) and activity loss. ${ }^{33}$

\section{Injection of Agonistic CD95-Specific Antibody}

Mice were injected intravenously, under brief ether anesthesia, with antibodies suspended in $200 \mu$ l sterile isotonic saline solution. Antibodies were either purified hamster $\mathrm{mAb}$ 
against mouse CD95 (JO2 clone, IgG isotype, containing $<0.01 \mathrm{ng}$ lipopolysaccharide (LPS) $/ \mu \mathrm{g}$ antibody) or purified control hamster monoclonal IgG, purchased from Pharmingen (San Diego, CA, USA).

\section{Histology}

Killed mice were immediately dissected and specimens from oral mucosa (tongue) were immediately cut into two parts: one was fixed in $2 \%$ glutaraldehyde in cacodylate buffer, and the second part was fixed in $10 \%$ formalin and further processed for paraffin embedding. Analysis of the intensity, distribution and composition of the inflammatory infiltrate was performed on $3 \mu \mathrm{m}$-thick paraffin section stained with hematoxylin and eosin. For the analysis of epithelial and endothelial cell death, specimens fixed in glutaraldehyde were post-fixed in osmium tetraoxide, dehydrated and then embedded in Epon 812 embedding media (Electron Microscopy Sciences, WA, USA). One micrometer thick sections were cut on a Leica ultracut microtome (Leica), counterstained with Toluidine blue. Apoptosis was confirmed in situ by detection of fragmented DNA, using the terminal deoxytransferasecatalyzed DNA nick-end labeling (TUNEL) assay. ${ }^{34}$ Three micrometer thick-paraffin sections were treated for $4 \mathrm{mn}$ at $37^{\circ} \mathrm{C}$ with proteinase $\mathrm{K}(20 \mu \mathrm{g} / \mathrm{ml})$ (Ventana laboratory, Tucson, AZ, USA). They were then incubated for $12 \mathrm{mn}$ at $20^{\circ} \mathrm{C}$ with a mix of terminal deoxynucleotidyl transferase (TdT) (Roche laboratory, Mannheim, Germany), digoxigenin-labeled UTP and dATP (Roche laboratory). Staining was achieved with an indirect immunoperoxydase method using incubation for $30 \mathrm{~min}$ at room temperature with an antibody directed against digoxigenin at 1/600 dilution (Roche laboratory). Final counterstaining was performed with hematoxylin. Immunohistochemical staining of the inflammatory infiltrate was performed on $5 \mu \mathrm{m}$-thick frozen sections, using anti-CD3 (hamster anti-mouse, clone 1452C11, BD Biosciences, Pharmigen), -CD4 (rat anti-mouse, clone RM4-5, BD Biosciences, Pharmigen), -CD8 (rat antimouse, clone 53-6.7, BD Biosciences, Pharmigen), -CD11 (rat anti-mouse, clone M1/70, BD Biosciences, Pharmigen), -CD31 (rat anti-mouse, clone MEC 13.3, Biosciences, Pharmigen), -perforin (rabbit anti-mouse, polyclonal (H-315): sc-9105, Santa Cruz Biotechnology, INC), the anti-hamster, anti-rat Ig, horse radish peroxidase (HRP) detection Kits (BD Biosciences, Pharmigen) and polyclonal goat antirabbit Immunoglobulins/HRP (DakoCytomation) according to the manufacturer's instructions.

\section{Quantification of the Cellular Infiltrate, of Epithelial-Cell Death and of Vascular Lesions}

Histopathological analyses were performed under an Olympus Provis optical microscope. Two pathologists, who were blinded to the experimental treatment, independently assessed slides with a $\times 200$ magnification for infiltrate quantification (number of mononuclear cells per field) and with $\times 400$ magnification for the evaluation of epithelial lesions (numbers of dead basal and para-basal keratinocytes) and vascular lesions (numbers of capillaries in which endothelial cells were either apoptotic or lacking) and between $\times 200$ and $\times 400$ magnification for phenotypic characterization of tissue infiltrating mononuclear cells. In each experimental condition, counts were performed on tissue sections from four to six mice, and percentages of damaged blood vessels, and numbers of infiltrating cells and of dead epithelial cells were the mean \pm standard deviation of the counts performed by the two pathologists. Statistical significance was assessed using the Wilcoxon test.

\section{RESULTS}

Endothelial Cell Death Precedes the Induction of Epithelial Cell Death in the Oral Mucosa during aGVHD in the Absence of any Conditioning Treatment

Injection of $2.5 \times 10^{7}$ allogeneic lymphocytes into SCID recipient mice in the absence of any conditioning treatment led within 2 weeks to characteristic clinical features of aGVHD, including major body weight loss (15\%) (Figure 1). In contrast, injection of $2.5 \times 10^{7}$ syngeneic lymphocytes did neither induce any weight loss nor any other clinical manifestation of aGVHD, such as posture modification (hunching) or activity loss ${ }^{33}$ during the follow-up period of 45 days (data not shown). Using this experimental model of progressive induction of aGVHD, ${ }^{22}$ we investigated the oral mucosa of the recipient mice by performing a kinetic ex-

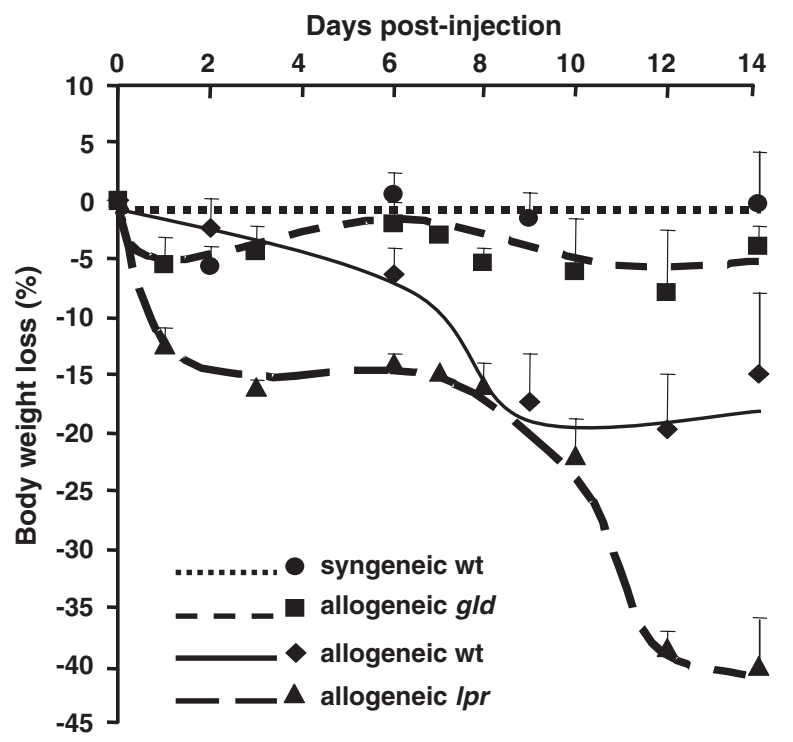

Figure 1 Transfer of allogeneic lymphocytes induces body weight loss, a clinical feature of aGVHD. Immunodeficient SCID mice were injected with $2.5 \times 10^{7}$ lymphocytes from syngeneic wt mice or with $2.5 \times 10^{7}$ lymphocytes from either allogeneic wt mice, gld mice that are defective in CD95L, or Ipr mice that are defective in CD95, but express functional CD95L. All allogeneic mice were from the same $\mathrm{C57BL} / 6$ genetic background. Body weight was measured for each mouse during a period of 14 days. Results are expressed as percentages of body weight loss, and are mean \pm s.d. of measurement in groups of six mice each. 
periment. We killed SCID recipients of $2.5 \times 10^{7}$ allogeneic lymphocytes either at day 3, 7, 11 or 14 after the lymphocyte transfer and analyzed tissue sections of the tongue. As controls, we used both SCID mice that did not receive any lymphocyte transfer and SCID recipients of $2.5 \times 10^{7}$ syngeneic lymphocytes killed at day 14 after transfer. In recipient mice killed 14 days after transfer of allogeneic lymphocytes, oral mucosa showed typical lesions with basal and para-basal keratinocyte-cell death, associated with a mononuclear cell infiltrate in the chorion, and endothelial-cell death in the chorion capillaries (Figure 2). Quantitative analysis indicated that the vascular lesions were extensive, $79 \pm 4.6 \%$ capillaries being damaged (Figure 3) with either apoptotic endothelial cells or no detectable remaining endothelial-cell lining. In contrast, we detected no significant basal or para-basal keratinocyte-cell death, cellular infiltration or vascular lesions $(9.71 \pm 4.2 \%$ damaged blood vessels) in the oral mucosa of recipient mice killed 14 days after transfer of $2.5 \times 10^{7}$ syngeneic lymphocytes (Figures 2 and 3 ).

We then investigated the respective kinetics of the induction of vascular lesions, epithelial-cell death and mononuclear-cell infiltration. We detected no significant vascular and epithelial lesions and no significant increase in numbers of infiltrating cells in the oral mucosa from recipient mice killed 3 days after transfer of allogeneic lymphocytes when compared with controls (Figures 2 and 3). At day 7 after transfer of allogeneic lymphocytes, no induction of basal keratinocyte-cell death was detected (Figures 2 and 3). In contrast, vascular lesions were already extensive (Figure 2), with more than $45 \%$ damaged capillaries in the chorion $(P<0.01$ when compared with control recipients of syngeneic lymphocytes) (Figure 3). Infiltrating mononuclear cells were observed at day 7 after transfer of allogeneic lymphocytes (Figure 2), though inter-individual variations resulted in a lack of significant differences when compared with controls (Figure 3). At day 11 after transfer of allogeneic lymphocytes, vascular lesions reached a plateau with around $80 \%$ damaged capillaries (Figure 3), whereas numbers of dead basal and para-basal keratinocytes and numbers of infiltrating mononuclear cells per field were significantly increased above controls $(P<0.02)$ (Figure 3$)$, but still less than half the levels reached at day 14 after allogeneic lymphocyte transfer (Figure 3).

To further confirm the temporal dissociation between this early onset of endothelial-cell apoptosis, and the subsequent onset of epithelial-cell apoptosis, we used transfers of higher numbers $\left(10^{8}\right)$ of allogeneic lymphocytes, which induce a very acute and rapid form of GVHD. ${ }^{22}$ Injection of $10^{8}$ allogeneic lymphocytes into SCID recipient mice induced hunching and activity loss during the first 2 days, followed by death 3 days or 4 days after the transfer. In recipient SCID mice killed 1 day after the transfer of $10^{8}$ allogeneic lymphocytes, vascular lesions were already induced, whereas no significant basal or para-basal keratinocyte death was detected (Figure 4a). In recipient mice killed 2 days after transfer of allogeneic lymphocytes, both vascular damage and basal keratinocyte death were present (Figure 4a), and TUNEL analysis showed extensive apoptosis in both the basal epithelium and the chorion (Figure $4 \mathrm{~b}$ ).

To further document endothelial-cell death, we performed immunohistochemical analysis of the CD31 endothelial-cell surface molecule. We have shown previously that the injection of the agonistic CD 95-specific JO2 mAb induces rapid and extensive endothelial-cell death. ${ }^{22}$ Using JO2 injection as a positive control, we confirmed the disappearance of CD31 staining on blood vessels from oral mucosa $2 \mathrm{~h} 30$ minutes after antibody injection (Figure 5). We then explored SCID recipient mice after transfer of $10^{8}$ allogeneic lymphocytes. As another positive control, we used CD31 staining to confirm the previously reported ${ }^{22}$ induction of vascular lesions in the liver of recipients killed either 1 day or 2 days after the allogeneic lymphocyte transfer (Supplementary Figure 1). In the recipient mice killed one day after transfer of $10^{8}$ allogeneic lymphocytes, CD31 staining indicated the induction of vascular lesions in the oral mucosa, including ectasia, dilatation, loss of vascular continuity, in particular in capillaries and a reduction in the numbers of stained vessels (Figure 6). In the recipient mice killed 2 days after the transfer, CD31 staining revealed a complete loss of endothelial cells in the oral mucosa (Figure 6). This confirmed that endothelial-cell death was the first detectable tissue lesion induced in the oral mucosa during this very acute form of GVHD.

\section{Analysis of the Mononuclear Cells Infiltrating the Oral Mucosa and the Spleen during aGVHD}

Our findings raised the question of the nature of the immune effector mononuclear cells that were recruited to the oral mucosa tissues during aGVHD in the absence of any conditioning treatment. To address this question, SCID recipients of $2.5 \times 10^{7}$ allogeneic lymphocytes were killed either at day 3, 7 or 12 after lymphocytes transfer and frozen tissue sections of the oral mucosa were analyzed using immunohistochemical detection of the CD11 monocyte/macrophage cell surface molecule, of the CD3 T lymphocyte cell surface molecule, and of the CD4 (helper T lymphocyte phenotype) and CD8 (cytotoxic T-lymphocyte phenotype) cell surface molecules. As controls, we used SCID mice that did not receive any lymphocyte injection. At day 3 after the transfer of allogeneic lymphocytes, we observed infiltrating cells of monocyte/macrophage phenotype, with few T lymphocytes, which included CD8 cells (Figure 7). Thus, despite the absence of any significant increase in the numbers of tissue infiltrating mononuclear cells detected by quantitative analyses of haematoxylin and eosin stained paraffin sections (Figure 3), immunohistochemical analysis of mononuclearcell phenotype on frozen sections (Figure 7) indicated that tissue infiltration of monocytes/macrophages, and of a few CD4 and CD8 cells, already occurred at the early time point (day 3 ) at which significant vascular damage was induced. At day 7 after the transfer of allogeneic lymphocytes, $\mathrm{T}$ lym- 


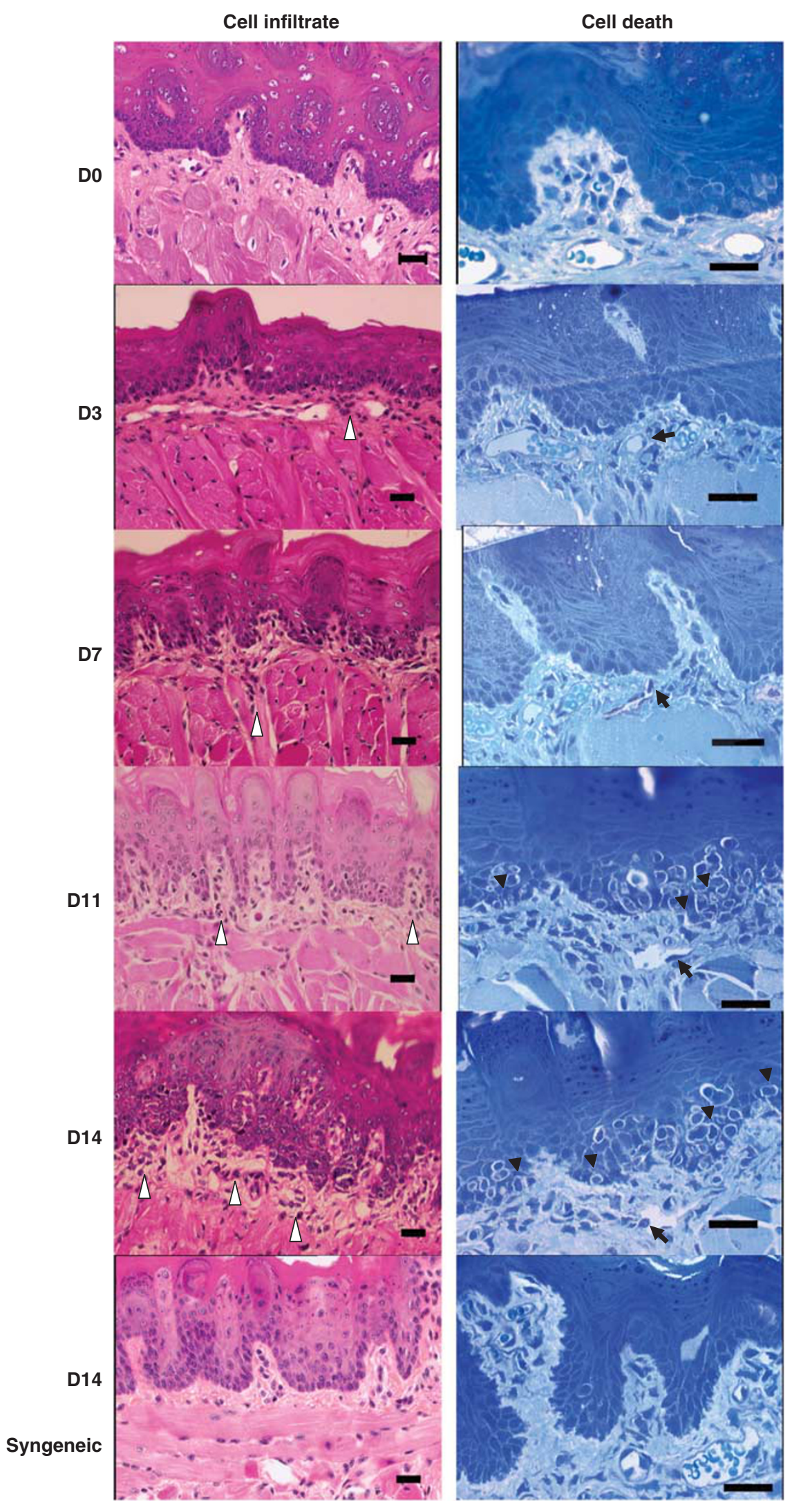

Figure 2 Early induction of endothelial-cell death in the oral mucosa during aGVHD. Haematoxylin and eosin staining of paraffin sections (cell infiltrate) or semi-thin sections of Epon-embedded (cell death) of the tongue mucosa of immunodeficient SCID mice in the absence of any lymphocyte transfer (D0); 3 days (D3), 7 days (D7), 11 days (D11) or 14 days (D14) after transfer of $2.5 \times 10^{7}$ lymphocytes from allogeneic wt mice; or 14 days after transfer of $2.5 \times 10^{7}$ lymphocytes from syngeneic wt mice (D14 syngeneic). White arrow heads indicate the cellular infiltrate; black arrows indicate dead endothelial cells; and black arrows heads indicate dead basal and para-basal keratinocytes (bar scale $=50 \mu \mathrm{m}$ ). 

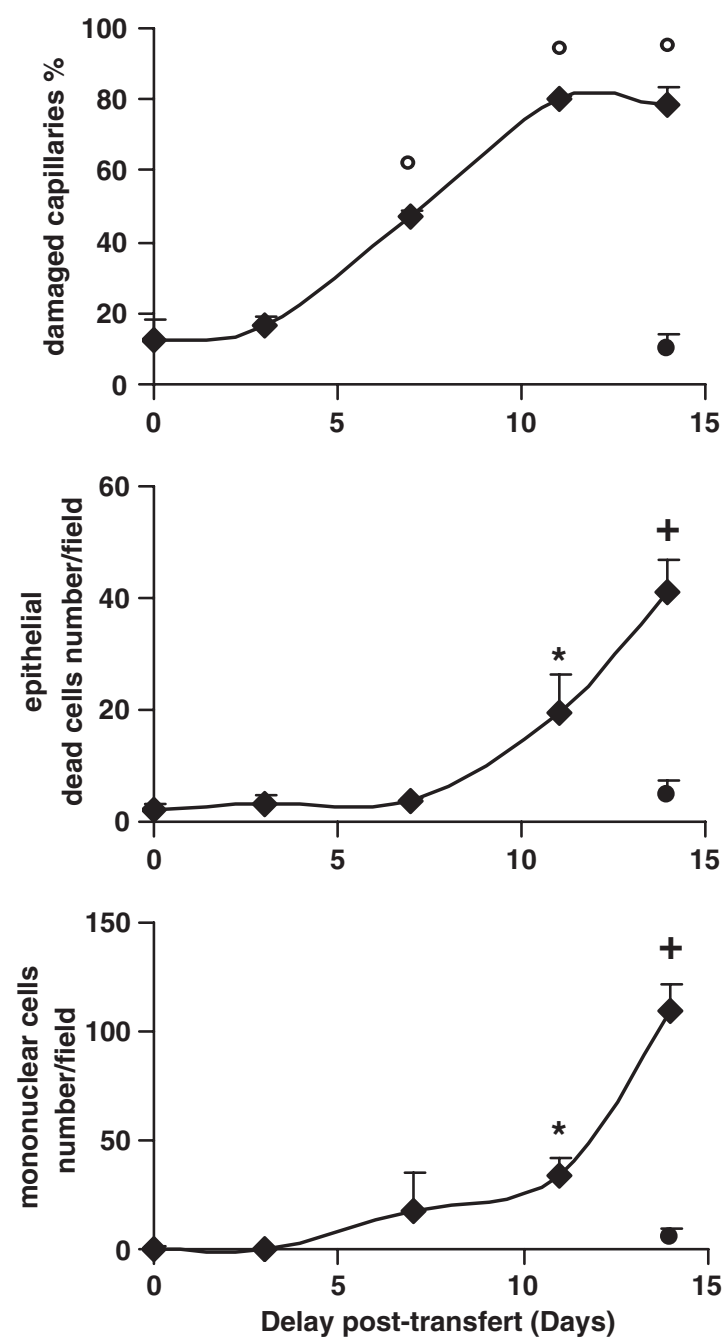

Figure 3 Endothelial-cell death precedes the induction of epithelial-cell death in the oral mucosa during aGVHD. A kinetic and quantitative analysis of the percentages of damaged capillaries, the numbers of dead basal and para-basal keratinocytes, and the numbers of infiltrating cells was performed in the tongue mucosa of SCID mice in the absence of any lymphocyte transfer (D0) $(n=4) ; 3$ days $(n=4), 7$ days $(n=4), 11$ days $(n=4)$ or 14 days $(n=5)$ after transfer of $2.5 \times 10^{7}$ lymphocytes from allogeneic wt mice; or 14 days after transfer of $2.5 \times 10^{7}$ lymphocytes from syngeneic wt mice $(n=4)$ (bottom circles, day 14). Percentages and numbers are mean \pm s.d. of two independent counts on tissue sections from $(n)$ different mice, as described in the Materials and methods section. ${ }^{\circ} P<0.01,{ }^{+} P<0.011$ and ${ }^{*} P<0.02$ compared to SCID recipients of syngeneic lymphocytes (Wilcoxon test).

phocytes became almost as numerous as the monocytes/ macrophages, and included both CD4 cells and CD8 cells (Figure 7). At day 12 after the transfer of allogeneic lymphocytes, an intense infiltration was still present, composed of monocytes/macrophages and T lymphocytes, and including CD4 and CD8 cells (Figure 7). These cells mainly infiltrated the dermis-epidermis junction and the chorion (Figure 7).
At this time point, day 12 after the transfer of $2.5 \times 10^{7}$ allogeneic lymphocytes, CD4 and CD8 cells were still present in the spleen of the SCID recipient mice (Supplementary Figure 2) and immunohistochemical staining using antiperforin antibodies showed the presence of activated, perforin-expressing immune effectors cells (Supplementary Figure 3). Immunohistochemical analysis also revealed the presence of perforin-expressing effectors cells in the oral mucosa at the same time point (Supplementary Figure 3). In contrast, perforin-expressing cells were neither detected in the spleen nor in the oral mucosa of SCID recipient mice 12 days after the transfer of $2.5 \times 10^{7}$ syngeneic lymphocytes (Supplementary Figure 3 ). Thus, aGVHD involved infiltration of activated immune effectors cells in both the lymphoid organs and the oral mucosa.

A recent study in a murine model of aGVHD has indicated that the homing of allogeneic lymphocytes in the spleen is a very early event that can be detected one day after lymphocyte transfer. ${ }^{35}$ To assess in our model the kinetics of the homing of allogeneic lymphocytes to the spleen, and to investigate their activation state, we performed immunohistochemical analysis of CD4, CD8 and perforin expression in the spleen of SCID recipient mice 1 day and 2 days after transfer of $10^{8}$ allogeneic lymphocytes. At both time points, CD4 and CD8 cells (Supplementary Figure 2), as well as perforin expressing effectors cells (Supplementary Figure 3) were detected in the spleen. Thus, the homing of immune cells to the lymphoid organs, and their activation into effectors cells, appear to be early events in this very acute form of GVHD.

\section{CD95L Expression by Allogeneic Lymphocytes is Required for the Induction of both Endothelial and Epithelial Cell Death in the Oral Mucosa}

Several reports have indicated a major role for CD95L in the pathogenesis of epithelial-cell death in murine models of aGVHD, ${ }^{4,18,20-22}$ and we have identified previously a crucial role for CD95L in the pathogenesis of aGVHD, through the early induction of disseminated endothelial-cell death and vascular damage. ${ }^{22}$

Our findings reported here indicated that endothelial cells from the oral mucosa are as sensitive to CD95-mediated death in response to the agonistic CD95-specific JO2 $\mathrm{mAb}$ (Figure 5) as endothelial cells from other organs and tissues. $^{22}$ Because caspase- 8 is the most proximal caspase activated downstream of CD95L-mediated engagement of the CD95 death receptor, ${ }^{36}$ we investigated whether inhibition of caspase- 8 activity may prevent the induction of endothelial and/or epithelial cell death. We treated SCID recipient mice with the caspase- 8 inhibitor peptide z-IETD $(500 \mu \mathrm{g}) 2 \mathrm{~h}$ before and 1 day after transfer of $10^{8}$ allogeneic lymphocytes from wt mice. In the z-IETD-treated recipient mice killed 2 days after the transfer of wt allogeneic lymphocytes, we observed very few vascular damage (Figure 8). However, the prevention of epithelial-cell death was less complete than that 
a
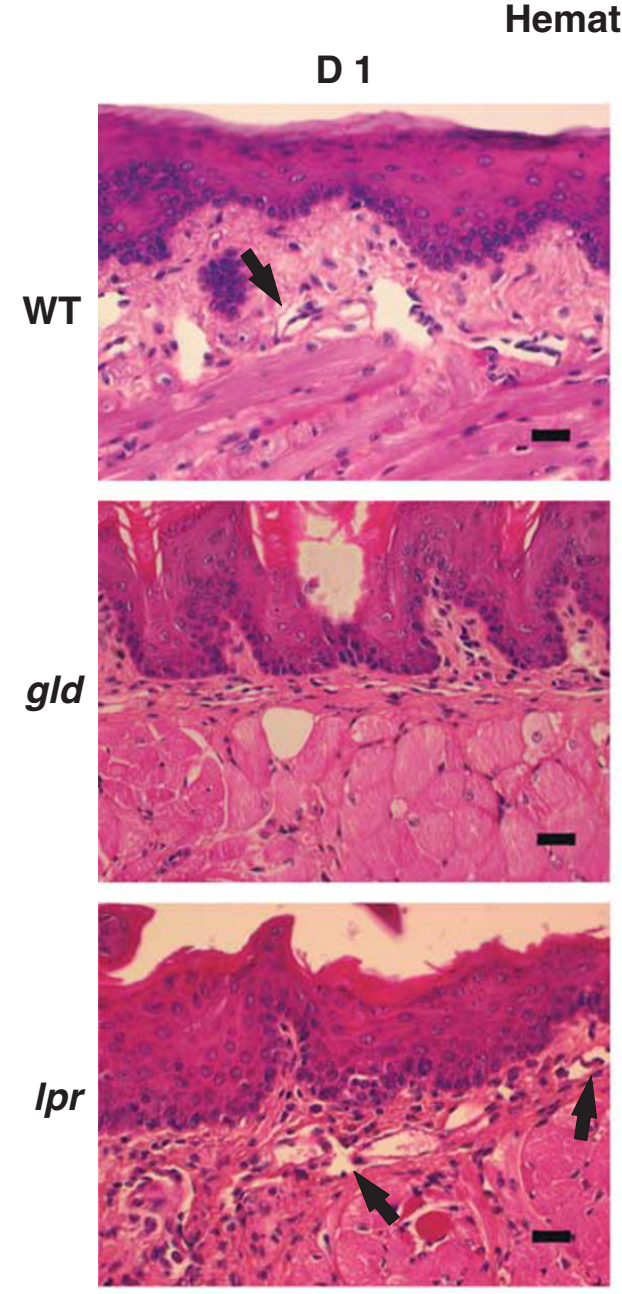

D 2
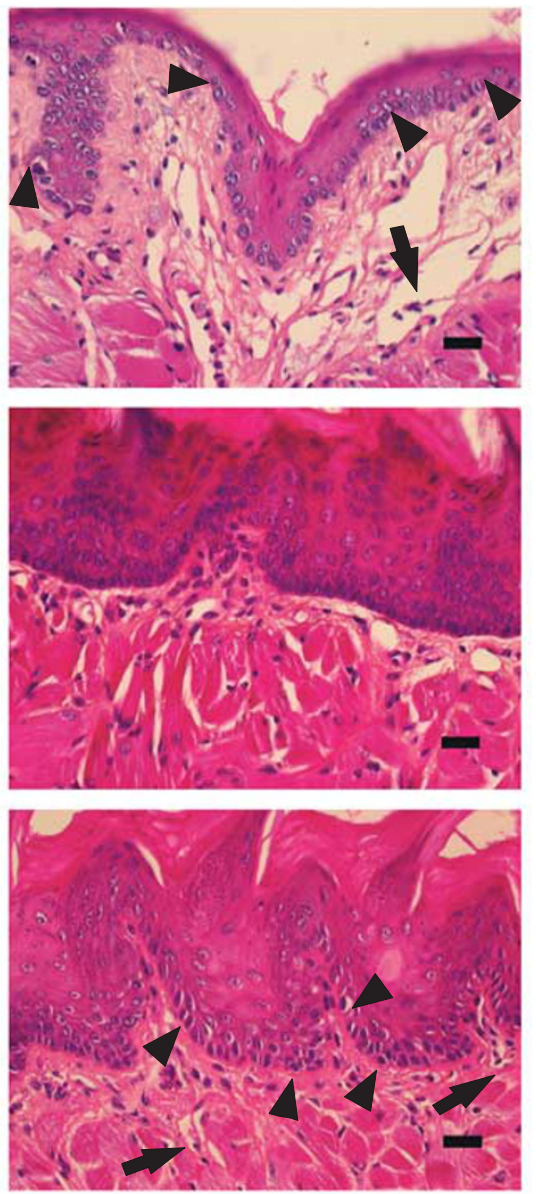

b
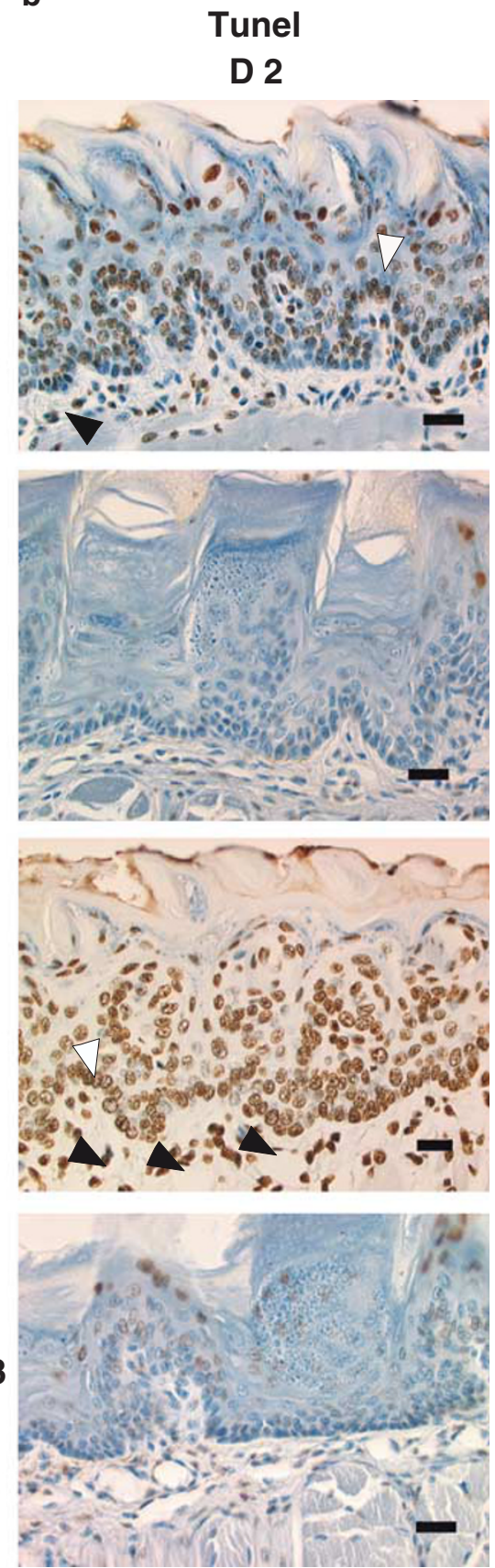

Figure $4 \mathrm{CD} 95 \mathrm{~L}$ expression by allogeneic lymphocytes is required for the induction of both vascular and epithelial lesions in the oral mucosa during aGVHD. (a) Haematoxylin and eosin staining sections of tongue mucosa of SCID recipients 1 day (D1) and 2 days (D2) after transfer of $10^{8}$ allogeneic lymphocytes from either wt mice (WT), CD95L-defective gld mice ( $g / d)$, or CD95-defective $/ p r$ mice (Ipr). Arrows indicate endothelial-cell death and arrow heads indicate basal and para-basal keratinocyte death. No infiltration is observed (bar scale $=50 \mu \mathrm{m}$ ). (b) TUNEL assay shows apoptotic cells (brown staining) (non apoptotic cells being stained in blue) in the tongue mucosa of SCID recipients 2 days after transfer of $10^{8}$ allogeneic lymphocytes from either wt mice (WT), CD95L-defective gld mice ( $g / d)$, or CD95-defective Ipr mice (lpr), or 2 days after transfer of $10^{8}$ allogeneic lymphocytes from wt mice and injection of the caspase-8 inhibitor peptide (caspase-8 inhibitor). Black arrows head indicate endothelial-cell apoptosis and white arrows head indicate basal keratinocyte apoptosis (bar scale $=50 \mu \mathrm{m}$ ).

of the vascular lesions, as more than $90 \%$ of the vascular damage induced by allogeneic lymphocytes was prevented in the presence of the caspase- 8 inhibitor peptide, whereas the prevention of epithelial-cell death achieved was only around
$65 \%$ (Figure 8). It is possible that this was due to the fact that the caspase- 8 inhibitor peptide, that we injected intravenously, was taken up by endothelial cells more effectively than by the extravascular epithelial cells. However, it is 

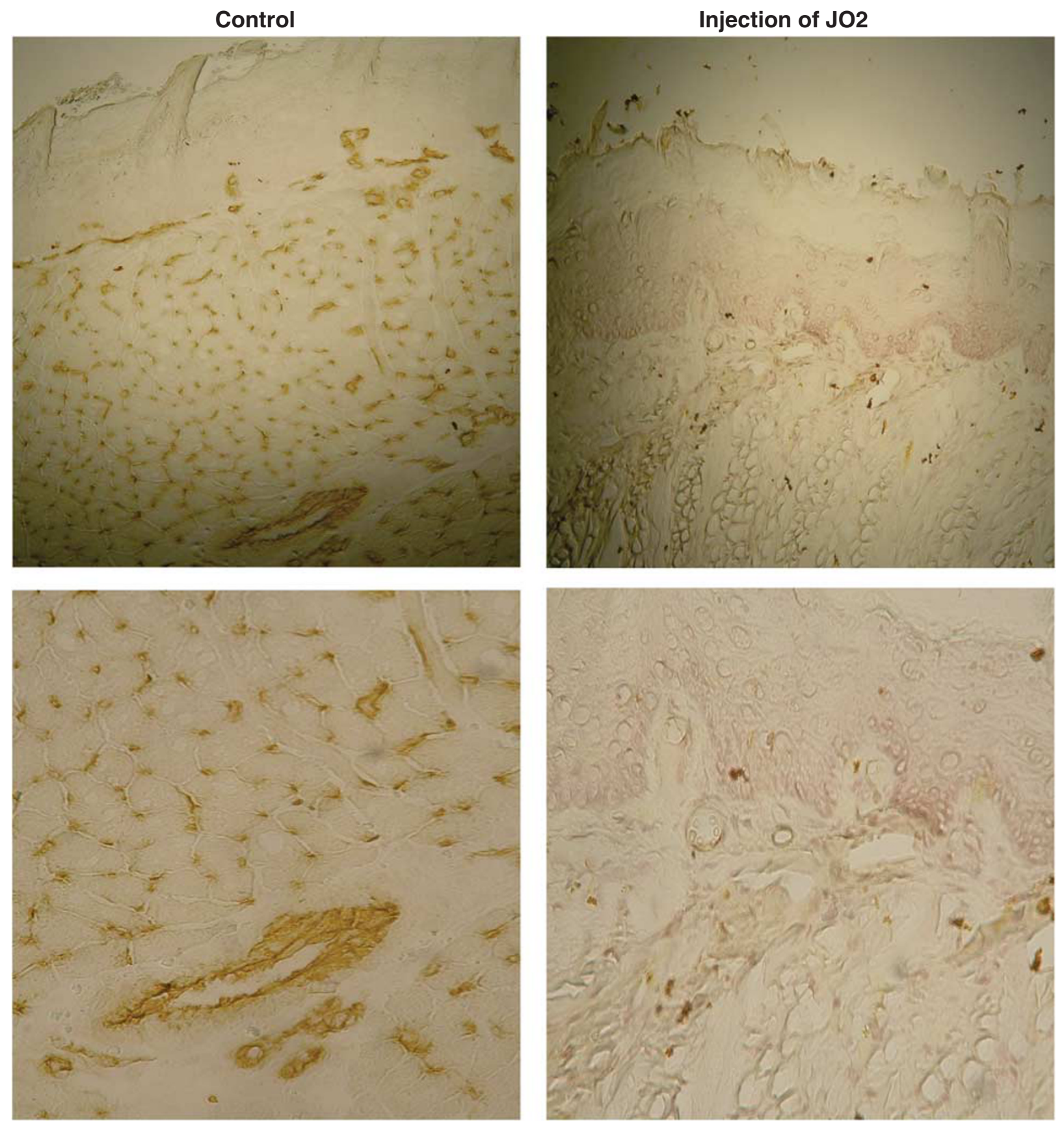

Figure 5 An agonistic CD95-specific mAb induces vascular lesions in the oral mucosa. Wild-type mice were injected intravenously with either the agonistic $\mathrm{JO} 2 \mathrm{CD} 95$-specific $\mathrm{mAb}(0.5 \mu \mathrm{g} / \mathrm{g}$ or $10 \mu \mathrm{g}$ for a $20 \mathrm{~g}$ mouse) or with control monoclonal IgG and killed $2.30 \mathrm{~h}$ after the injection. Immunohistochemical analysis of frozen sections of the oral mucosa, using CD31-specific antibodies (that stain endothelial cells), reveals the loss of endothelial cells following JO2 injection.

important to note that these results are difficult to interpret. Indeed, a recent report indicates that inhibition of caspase-8 activity may not only protect target cells from CD95Lmediated apoptosis, but also inhibit T-lymphocyte activation, ${ }^{37}$ and may thus interfere with the capacity of allogeneic T lymphocytes to induce aGVHD.

To further investigate whether CD95L may be involved in the early vascular and subsequent epithelial lesions induced by aGVHD in the oral mucosa, we transferred into SCID recipient mice $2.5 \times 10^{7}$ or $10^{8}$ allogeneic lymphocytes from either wt mice, gld mice that are defective in CD95L, or $l p r$ mice that are defective in CD95, but express functional CD95L; all these mice being from the same C57 BL/6 genetic background. Because CD95-defective $l p r$ mice have similar lymphocyte anomalies and develop similar time-dependent lymphoproliferative disorders as CD95L-defective gld mice, ${ }^{38}$ 
D1
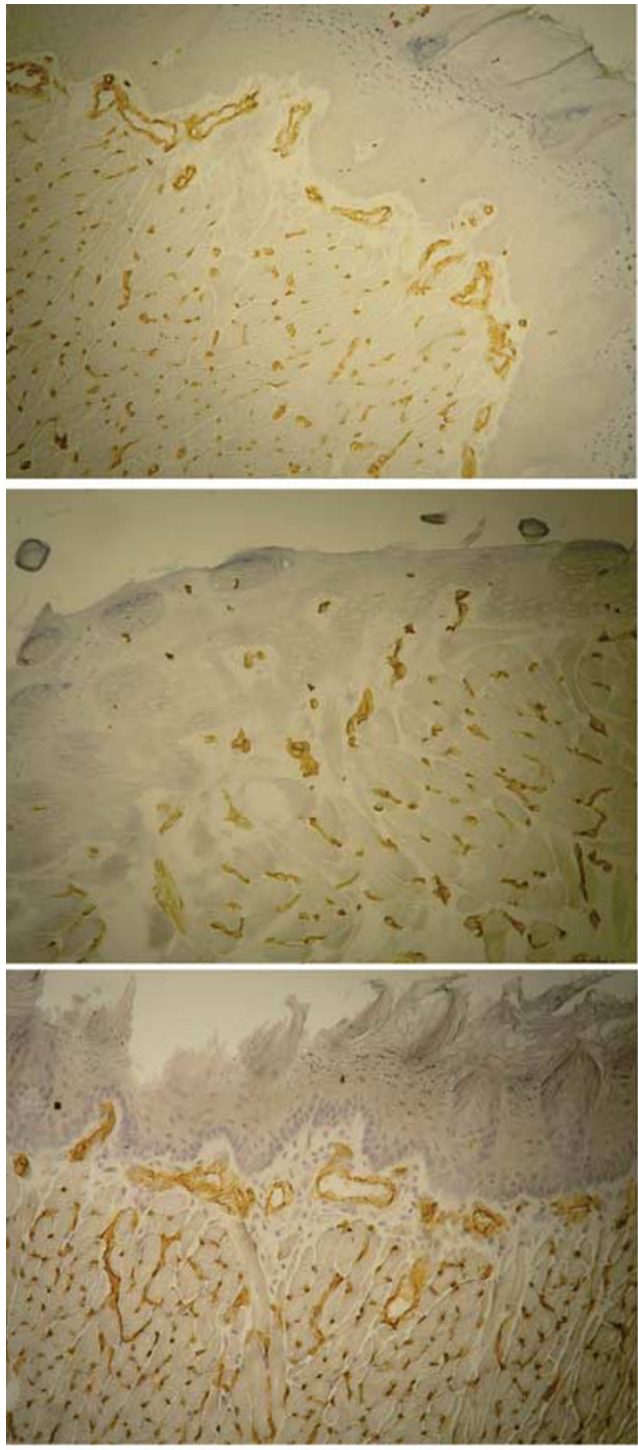

D2

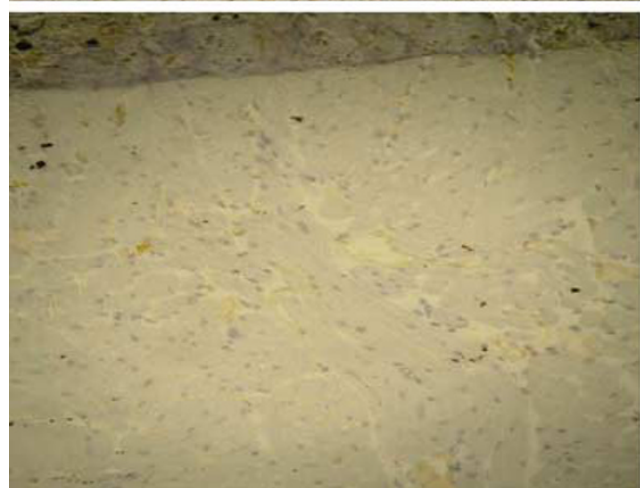

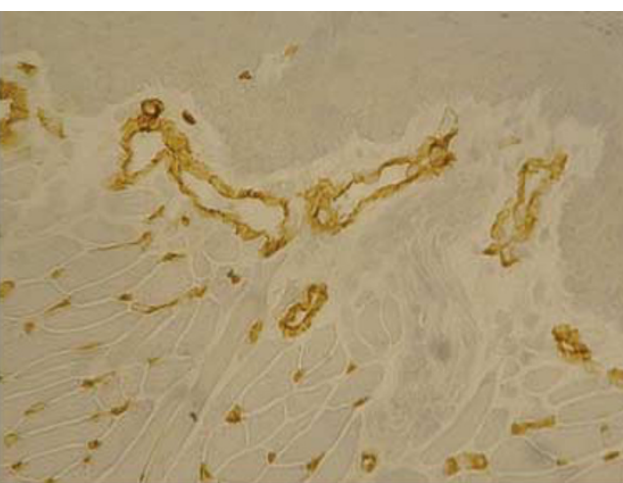
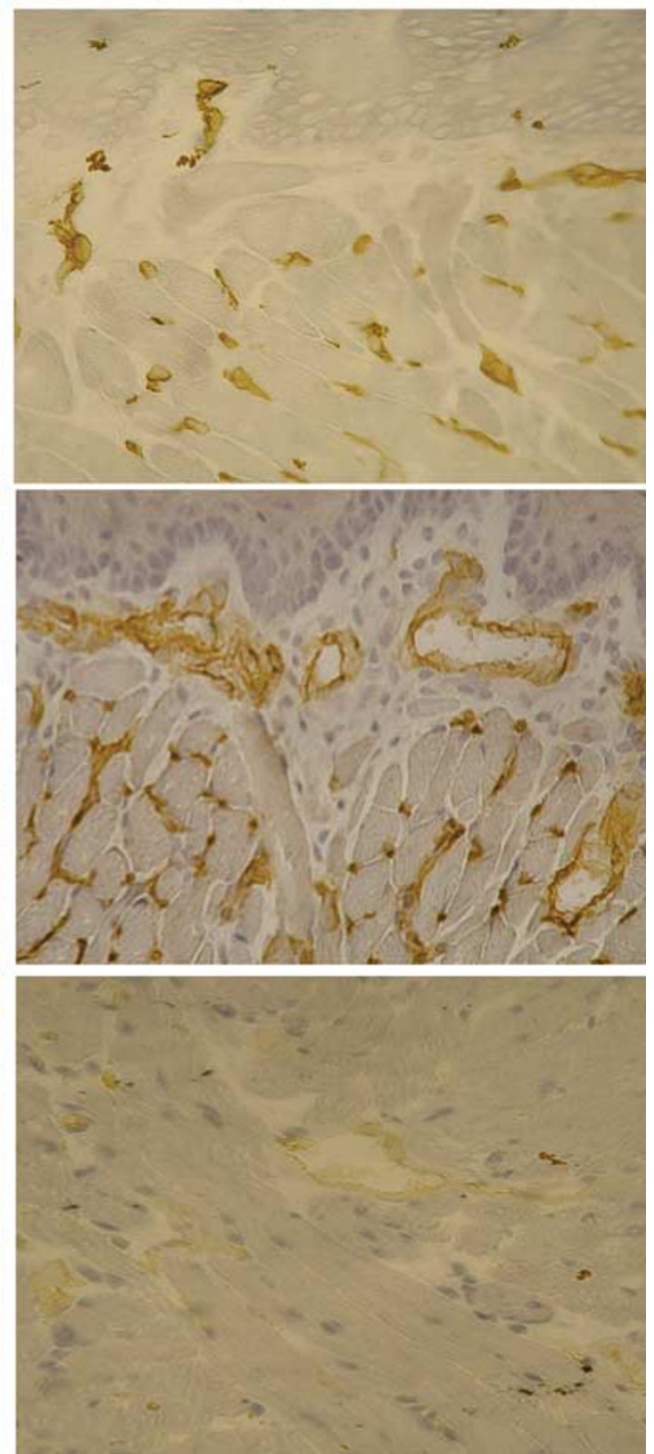

syngeneic

allogeneic

syngeneic

allogeneic

Figure 6 CD31 staining confirms the early induction of vascular lesions in the oral mucosa during aGVHD. Immunohistochemical analysis using anti-CD31 antibodies (that stain endothelial cells) of frozen tissue sections of the tongue mucosa of SCID mice 1 day (D1) or 2 days (D2) after transfer of $10^{8}$ lymphocytes from either syngeneic or allogeneic wt mice.

they represent the most relevant control for any potential additional functional anomaly of gld mice lymphocyte other than their lack of functional CD95L expression. In the recipient SCID mice after transfer of allogeneic gld lymphocytes, neither clinical features of aGVHD such as body weight loss (Figure 1) nor endothelial or epithelial lesions were 

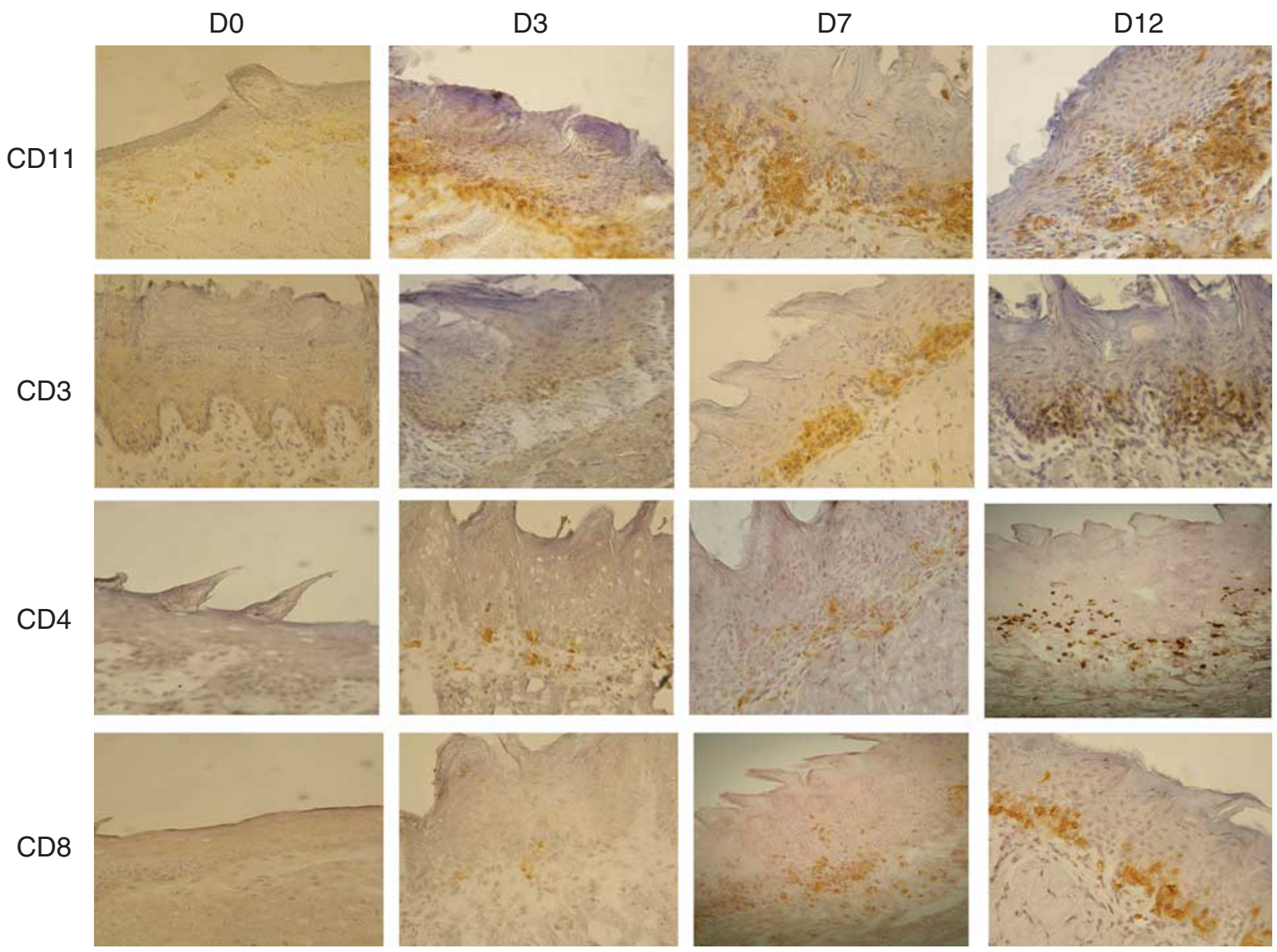

Figure 7 Phenotypic characterization of the mononuclear cells infiltrating the oral mucosa during aGVHD. Immunohistochemical staining (using anti-CD11, $-C D 3,-C D 4$, and -CD8 antibodies) of frozen tissue sections of the tongue mucosa of SCID mice in the absence of any lymphocyte transfer (D0); or 3 days (D3), 7 days (D7) or 12 days (D12) after transfer of $2.5 \times 10^{7}$ lymphocytes from allogeneic wt mice. Anti-CD11 antibody labels monocyte/macrophages; anti-CD3 labels T lymphocytes; anti-CD4 labels CD4 T lymphocytes and macrophages, which are morphologically distinguishable; and anti-CD8 labels CD8 T lymphocytes.

detected (Figures 4 and 8) when compared with control recipients of syngeneic wt lymphocytes. In contrast, body weight loss (Figure 1), as well as endothelial and epithelial lesions were extensive in recipients of allogeneic $l p r$, as in recipients of allogeneic wt lymphocytes (Figures 4 and 8). This indicated that CD95L, either expressed or released by allogeneic lymphocytes, is required for both the early induction of endothelial-cell death and the subsequent induction of epithelial-cell death.

\section{DISCUSSION}

Here, we identified the induction of endothelial-cell death and vascular damage in the oral mucosa as an early and major lesion caused by allogeneic lymphocytes in a murine model of aGVHD that does not involve a radiotherapy or chemotherapy-conditioning regimen. Our findings suggest the following sequence of events in the oral mucosa during aGVHD: (i) an early phase of endothelial-cell apoptosis induction with significant vascular damage, concomitant with the homing of perforin-expressing activated immune effec- tors cells in the lymphoid organs and the onset of tissue infiltration of lymphocytes and monocytes/macrophages in the oral mucosa; and (ii) a subsequent phase of epithelial cell death induction, associated with increasing vascular damage and tissue infiltration of CD4 and CD8 T lymphocytes and perforin-expressing activated immune effectors cells.

The implications of our findings for the pathogenesis of oral mucosa lesions during aGVHD can be summarized as follow: (i) endothelial-cell death and vascular damage precede the induction of epithelial-cell death; (ii) vascular damage is associated with the onset of tissue infiltration by allogeneic CD4 and CD8 T lymphocytes; (iii) endothelial cells from blood vessels in the oral mucosa are sensitive in vivo to CD95-mediated death induced by an agonistic CD95specific antibody; (iv) the expression of functional CD95L by the allogeneic lymphocytes is necessary for the induction of both the early endothelial-cell death and the subsequent epithelial-cell death in the oral mucosa.

CD95L-mediated pro-apoptotic signaling can be induced either by CD95L-expressing cells, or by soluble CD95L 

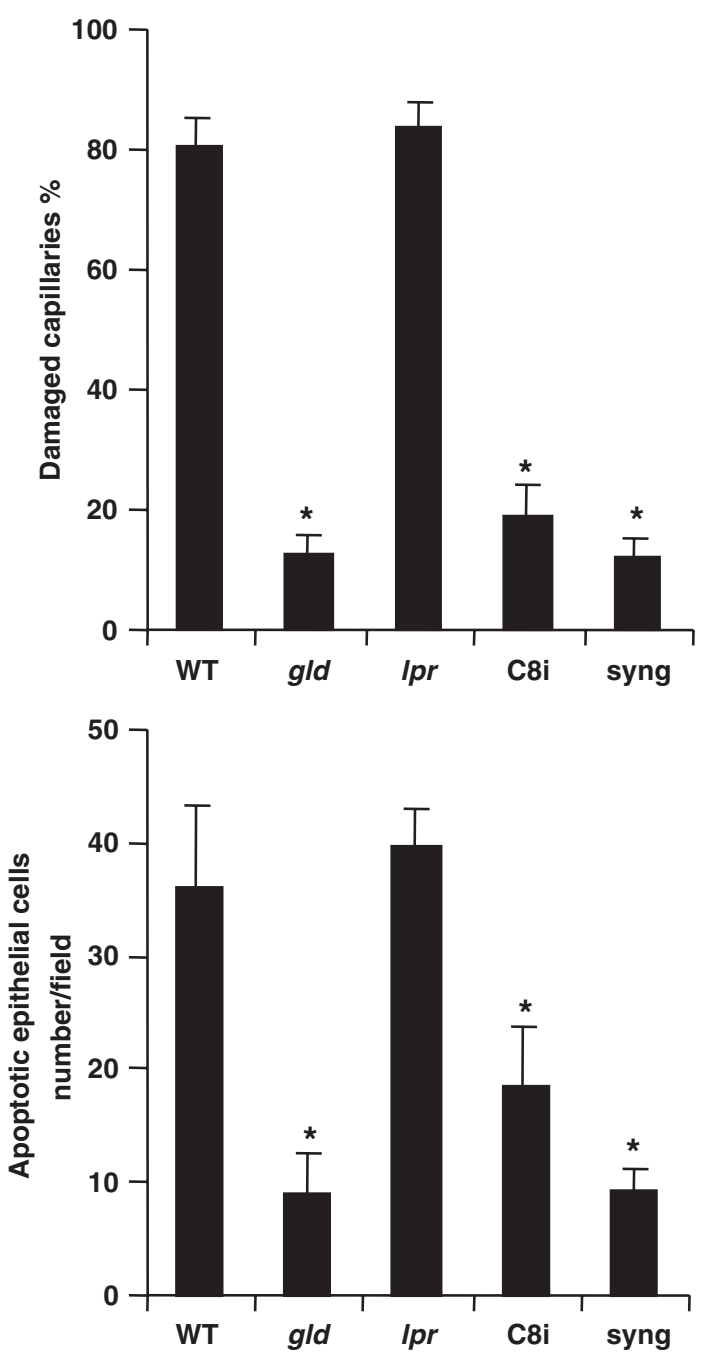

Figure 8 Quantitative analysis of the respective contribution of CD95L expression and caspase- 8 activation in the induction of both vascular and epithelial lesions in the oral mucosa during aGVHD. Percentages of damaged capillaries and numbers of dead basal and para-basal keratinocytes in the tongue mucosa of SCID recipients 2 days after transfer of $10^{8}$ allogeneic lymphocytes from either wt mice $(n=6)$, CD95L-defective gld mice ( $g l d)(n=4)$, or CD95-defective Ipr mice (Ipr) $(n=4)$; or 2 days after transfer of $10^{8}$ allogeneic lymphocytes from wt mice and injection of the caspase- 8 inhibitor peptide (C8i) $(n=4)$; or 2 days after transfer of $10^{8}$ syngeneic lymphocytes from wt mice (syng) $(n=4)$. Percentages and numbers are mean \pm s.d. of two independent counts on tissue sections from $(n)$ different mice, as described in Materials and methods section. ${ }^{\star} P<0.02$ compared to 1 (Wilcoxon test).

released by these cells. In situations of human, and mice MHC II mismatch, it has been reported that the precursor frequency of alloreactive effectors CD4 T lymphocytes causing host aGVHD is around 5\%. ${ }^{39}$ Our murine model of aGVHD, which involves a mismatch in both MHC I and MHC II might result in a similar precursor frequency in both CD4 and CD8 T lymphocytes. Such a 5\% frequency would correspond to $5 \times 10^{6}$ precursors of alloreactive effectors cells in the $10^{8}$ allogeneic lymphocytes that we injected into the immunodeficient SCID recipients. Whether such a number of effector lymphocytes might allow during the first $24 \mathrm{~h}$ the extensive induction of vascular lesions in the oral mucosa through direct killing of endothelial cells by circulating alloreactive lymphocytes, or whether it involves the release by the activated allogeneic lymphocytes of soluble CD95L able to act at a distance remains to be assessed.

The capacity of soluble CD95L to trigger apoptosis, however, depends on its multimerization degree, ${ }^{40,41}$ that determines the CD95 receptor multimerization, and hence the signaling it induces in the target cells. CD95L-expressing cells can release CD95L either as a soluble, metalloproteaseprocessed form, or as a microvesicle-bound unprocessed form $^{42-44}$ that has been reported to exert more potent pro-apoptotic effects. ${ }^{43}$ Activated living ${ }^{44}$ or dying ${ }^{42} \mathrm{~T}$ lymphocytes have been reported to release CD95L-expressing microvesicles. We have recently documented the in vitro release of such CD95L-bearing microvesicles by human lymphocytes that are undergoing apoptosis. ${ }^{45}$ However, these microvesicles acted as cofactors for apoptosis induction were not sufficient by themselves to cause cell death, at least in our in vitro model system. ${ }^{45}$ Therefore, it remains to be assessed, whether in addition to the involvement of CD95L expressed and/or released by activated allogeneic lymphocytes, other effector mechanisms may cooperate with CD95L in the induction of the early vascular lesions during aGVHD. Although perforin has been described as a major effector of graft-versus-leukemia (GVL) reactions rather than of aGVHD, ${ }^{4,20,21}$ it has also been reported to synergize with CD95L in the induction of epithelial lesions in the skin and liver during aGVHD., ${ }^{3,17,46}$ Thus, perforin released by activated allogeneic lymphocytes might represent one of the candidate mechanisms that could synergize with CD95L in the induction of vascular damage.

It remains to be assessed whether endothelial-cell death is also an early and major feature of oral mucosa damage during human aGVHD. Provided that this is the case, it is important to note that the conditioning treatment used for human bone marrow transplantation may by itself synergize with these immune-mediated lesions. Indeed, chemotherapy has been reported to induce endothelial-cell lesions, ${ }^{47,48}$ and more recently, radiotherapy has also been shown to induce endothelial-cell apoptosis. ${ }^{49}$ Interestingly, endothelial-cell apoptosis induced in the gastro-intestinal tract by radiation has been found to constitute the primary lesion responsible, in a murine model, for the subsequent induction of epithelial stem-cell death and lethal gastro-intestinal syndrome. ${ }^{49}$ Thus, it is tempting to speculate that the early induction of CD95Lmediated vascular damage that we have identified here may by itself play a role in the development of the subsequent epithelial damage in the oral mucosa during aGVHD, through the induction of hypoxia and/or vascular leakage of immune cells or soluble proapoptotic molecules.

Finally, it should be noted that basal and para-basal keratinocyte death in the oral mucosa is not only a characteristic 
feature of aGVHD, but also of other diseases affecting the oral mucosa, such as Behcet syndrome, paraneoplasic oral mucosa dysplasia, in situ carcinoma, oral erythema multiforme ${ }^{50-55}$ and typical cutaneous adverse drug reactions, such as Stevens-Johnson syndrome, that has been reported to be induced by soluble CD95L. ${ }^{56}$ Whether early CD95Lmediated endothelial-cell death and vascular damage may also be involved in the pathogenesis of these diseases is an interesting possibility that remains to be investigated.

Supplementary Information accompanies the paper on the Laboratory Investigation website (http://www.laboratoryinvestigation.org)

\section{ACKNOWLEDGEMENT}

We thank Pascal Nicole, Luc Legrès, Fathia Bouhidel and Premavathy Rajagopalan-Levasseur for their technical assistance. This work was supported by Institut National de la Santé et de la Recherche Médicale (INSERM), Université Paris 7, Assistance Publique-Hôpitaux de Paris (AP-HP), and by grants from Association de recherches sur le Cancer (ARC) (to AJ) and Etablissement Français des Greffes (EFG), Agence Nationale de Recherche sur le SIDA (ANRS), Ensemble Contre le SIDA (ECS) and Université Paris 7 Valorisation (to JCA).

\section{DUALITY OF INTEREST}

None declared.

1. Mitsuyasu RT, Champlin RE, Gale RP, et al. Treatment of donor bone marrow with monoclonal anti-T-cell antibody and complement for the prevention of graft-versus-host disease. A prospective, randomized, double-blind trial. Ann Intern Med 1986;105:20-26.

2. Atkinson $\mathrm{K}$, Biggs J, Cooley $\mathrm{M}$, et al. A comparative study of T-cell depleted and non-depleted marrow transplantation for hematological malignancy. Aust NZ J Med 1987;17:16-23.

3. Baker MB, Riley RL, Podack ER, et al. The role of cell-mediated cytotoxicity in acute GVHD after MHC-matched allogeneic bone marrow transplantation in mice. J Exp Med 1996;183:2645-2656.

4. Van den Brink MR, Burakoff SJ. Cytolytic pathways in haematopoietic stem-cell transplantation. Nat Rev Immunol 2002;2:273-281.

5. Barrett AP. Oral complications of bone marrow transplantation. Aust NZ J Med 1986;16:239-240.

6. Barrett AP, Bilous AM. Oral patterns of acute and chronic graft-v-host disease. Arch Dermatol 1984;120:1461-1465.

7. Carl W, Higby DJ. Oral manifestations of bone marrow transplantation. Am J Clin Oncol 1985;8:81-87.

8. Kolbinson DA, Schubert MM, Flournoy $\mathrm{N}$, et al. Early oral changes following bone marrow transplantation. Oral Surg Oral Med Oral Pathol 1988;66:130-138.

9. Seto BG, Kim M, Wolinsky $L$, et al. Oral mucositis in patients undergoing bone marrow transplantation. Oral Surg Oral Med Oral Pathol 1985;60:493-497.

10. Schubert MM, Sullivan KM. Recognition, incidence, and management of oral graft-versus-host disease. NCI Monogr 1990;9:135-143.

11. Sale GE, Shulman HM, Schubert MM, et al. Oral and ophthalmic pathology of graft versus host disease in man: predictive value of the lip biopsy. Hum Pathol 1981;12:1022-1030.

12. Sale GE, Gallucci BB, Schubert MM, et al. Direct ultrastructural evidence of target-directed polarization by cytotoxic lymphocytes in lesions of human graft-vs-host disease. Arch Pathol Lab Med 1987;111:333-336.

13. Sale GE, Raff RF, Storb R. Stem cell regions in filiform papillae of tongue as targets of graft-versus-host disease. Transplantation 1994; 58:1273-1275.

14. Lishner M, Patterson B, Kandel R, et al. Cutaneous and mucosal neoplasms in bone marrow transplant recipients. Cancer 1990;65: 473-476.

15. Otsubo $\mathrm{H}$, Yokoe $\mathrm{H}$, Miya $\mathrm{T}$, et al. Gingival squamous cell carcinoma in a patient with chronic graft-versus-host disease. Oral Surg Oral Med Oral Pathol Oral Radiol Endod 1997;84:171-174.
16. Piguet PF, Grau GE, Allet B, et al. Tumor necrosis factor/cachectin is an effector of skin and gut lesions of the acute phase of graft-vs-host disease. J Exp Med 1987;166:1280-1289.

17. Braun MY, Lowin B, French $L$, et al. Cytotoxic $T$ cells deficient in both functional Fas ligand and perforin show residual cytolytic activity yet lose their capacity to induce lethal acute graft-versus-host disease. J Exp Med 1996;183:657-661.

18. Via CS, Nguyen P, Shustov A, et al. A major role for the Fas pathway in acute graft-versus-host disease. J Immunol 1996;157:5387-5393.

19. Hattori $\mathrm{K}$, Hirano $\mathrm{T}$, Miyajima $\mathrm{H}$, et al. Differential effects of anti-Fas ligand and anti-tumor necrosis factor alpha antibodies on acute graftversus-host disease pathologies. Blood 1998;91:4051-4055.

20. Tsukada N, Kobata T, Aizawa Y, et al. Graft-versus leukemia effect and graft-versus-host disease can be differentiated by cytotoxic mechanisms in a murine model of allogeneic bone marrow transplantation. Blood 1999;93:2738-2747.

21. Schmaltz C, Alpdogan O, Horndasch KJ, et al. Differential use of Fas ligand and perforin cytotoxic pathways by donor T cells in graftversus-host disease and graft-versus-leukemia effect. Blood 2001;97(9):2886-2895.

22. Janin A, Deschaumes C, Daneshpouy M, et al. CD95 engagement induces disseminated endothelial cell apoptosis in vivo: immunopathologic implications. Blood 2002;99:2940-2947.

23. Graubert TA, Russell JH, Ley TJ. The role of granzyme B in murine models of acute graft-versus-host disease and graft rejection. Blood 1996;87:1232-1237.

24. Sonis ST. Mucositis as a biological process: a new hypothesis for the development of chemotherapy-induced stomatotoxicity. Oral Oncol 1998;34:39-43.

25. Xun CQ, Thompson JS, Jennings CD, et al. Effect of total irradiation, busulfan-cyclophosphamide or cyclophosphamide conditioning on inflammatory cytokine release and development of acute and chronic graft-versus-host disease in $\mathrm{H}-2$ incompatible transplanted SCID mice. Blood 1994;83:2360-2367.

26. Korngold R, Sprent J. Surface markers of T cells causing lethal graft-vshost disease to class I vs class II H-2 differences. J Immunol 1985;135:3004-3010.

27. Korngold R, Sprent J. T cell subsets and graft-versus-host disease. Transplantation 1987;44:335-339.

28. Via CS, Sharrow SO, Shearer GM. Role of cytotoxic T lymphocytes in the prevention of lupus-like disease occurring in a murine model of graftvs-host disease. J Immunol 1987;139:1840-1849.

29. Dvorak HF, Mihm MC, Dvorak AM, et al. Rejection of first-set skin allografts in man. J Exp Med 1979;150:322-337.

30. Dumler JS, Beschorner WE, Farmer ER, et al. Endothelial-cell injury in cutaneous acute graft-versus-host disease. Am J Pathol 1989;135:1097-1103.

31. Biedermann BC, Sahner $S$, Gregor $M$, et al. Endothelial injury mediated by cytotoxic $T$ lymphocytes and loss of microvessels in chronic graft versus host disease. Lancet 2002;359:2078-2083.

32. Ertault-Daneshpouy $M$, Leboeuf $C$, Lemann $M$, et al. Pericapillary hemorrhage as criterion of severe human digestive graft-versus host disease. Blood 2004;103:4681-4684.

33. Cooke KR, Kobzik L, Martin TR, et al. An experimental model of idiopathic pneumonia syndrome after bone marrow transplantation: I. The roles of minor $\mathrm{H}$ antigens and endotoxin. Blood 1996;88:32303239.

34. Gavrieli Y, Sherman Y, Ben-Sasson SA. Identification of programmed cell death in situ via specific labeling of nuclear DNA fragmentation. J Cell Biol 1992;119:493-501.

35. Beilhack A, Schulz S, Baker J, et al. In vivo analyses of early events in acute graft-versus-host disease reveal sequential infiltration of T-cell subsets. Blood 2005:106:1113-1122.

36. Krammer P. CD95's deadly mission in the immune system. Nature 2000;407:789-795.

37. Su H, Bidere $\mathrm{N}$, Zheng $\mathrm{L}$, et al. Requirement for caspase-8 in NF- $\kappa \mathrm{B}$ activation by antigen receptor. Science 2005:307:1465-1468.

38. Nagata S. Apoptosis by death factor. Cell 1997;88:355-365.

39. Godfrey WR, Krampf MR, Taylor PA, et al. Ex vivo depletion of alloreactive cells based on CFSE dye dilution, activation antigen selection, and dendritic cell stimulation. Blood 2004;103:1158-1165.

40. Schneider P, Holler N, Bodmer JL, et al. Conversion of membranebound Fas (CD95) ligand to its soluble form is associated with 
downregulation of its proapoptotic activity and loss of liver toxicity. J Exp Med 1998;187:1205-1213.

41. Huang DCS, Hahne M, Schroeter $M$, et al. Activation of Fas by FasL induces apoptosis by a mechanism that cannot be blocked by Bcl-2 or Bcl-XL. Proc Natl Acad Sci USA 1999;96:1487114876.

42. Monleon I, Martinez-Lorenzo MJ, Monteagudo L, et al. Differential secretion of Fas ligand- or APO2 ligand/TNF-related apoptosisinducing ligand-carrying microvesicles during activation-induced death of human T cells. J Immunol 2001;167:6736-6744.

43. Andreola G, Rivoltini L, Castelli C, et al. Induction of lymphocyte apoptosis by tumor cell secretion of FasL-bearing microvesicles. J Exp Med 2002;195:1303-1316.

44. Martinez-Lorenzo MJ, Anel A, Gamen S, et al. Activated human T cells release bioactive Fas ligand and APO2 ligand in microvesicles. J Immunol 1999:163:1274-1281.

45. Lelièvre JD, Mammano F, Arnoult D, et al. A novel mechanism for HIV1mediated bystander CD4+ T-cell death: neighbouring dying cells drive the capacity of HIV1 to kill non-cycling primary CD4+ T cells. Cell Death and Differentiation 2004;11:1017-1027.

46. Kagi D, Vignaux F, Ledermann B, et al. Fas and perforin pathways as major mechanisms of T cell-mediated cytotoxicity. Science 1994;265:528-530.

47. Dahllof G, Heimdahl A, Modeer T, et al. Oral mucous membrane lesions in children treated with bone marrow transplantation. Scand J Dent Res 1989;97:268-277.
48. Antin JH, Ferrara JL. Cytokine dysregulation and acute graft-versushost disease. Blood 1992;80:2964-2968.

49. Paris F, Fuks Z, Kang A, et al. Endothelial apoptosis as the primary lesion initiating intestinal radiation damage in mice. Science 2001;293:293-297.

50. Birchall MA, Winterford CM, Allan DJ, et al. Apoptosis in normal epithelium, premalignant and malignant lesions of the oropharynx and oral cavity: a preliminary study. Eur J Cancer B Oral Oncol 1995;31B:380-383.

51. Boyd A, Nanney L, Cameron G, et al. Expression of bcl-2 in lichen planus, acute graft-versus-host disease, and erythema multiforme. Am J Dermatopathol 1997;19:46-51.

52. Chrysomali E, Greenspan JS, Dekker N, et al. Apoptosis associated proteins in oral hairy leukoplasia. Oral Dis 1996;2:279-284.

53. Chrysomali E, Lozada-Nur F, Dekker NP, et al. Apoptosis in oral erythema multiforme. Oral Surg Oral Med Oral Pathol Oral Radiol Endod 1997;83:272-280.

54. Honma T, Saito T, Fujioka Y. Possible role of apoptotic cells of the ora epithelium in the pathogenesis of aphthous ulceration. Oral Surg Oral Med Oral Pathol 1985:59:379-387.

55. Reich K, Brinck U, Letschert M, et al. Graft-versus-host disease like immunophenotype and apoptotic keratinocyte death in paraneoplastic pemphigus. Br J Dermatol 1999;141:739-746.

56. Abe R, Shimizu T, Shibaki A, et al. Toxic epidermal necrolysis and Stevens-Johnson syndrome are induced by soluble Fas ligand. Am J Pathol 2003;162:1515-1520. 